\title{
Prefinished Metal Polymer Hybrid Parts
}

Ines Kühnert'), Michaela Gedan-Smolka'), Matthieu Fischer ${ }^{11}$, Peter Scholz ${ }^{2}$, Dirk Landgrebe ${ }^{2)}$, Didier Garray3)

1) Leibniz-Institut für Polymerforschung Dresden e. V., kuehnert@ipfdd.de, Hohe Str. 6, 01069 Dresden, Germany

2) Fraunhofer-Institut für Werkzeugmaschinen und Umformtechnik IWU, Peter.Scholz@iwu.fraunhofer.de, Reichenhainer Straße 88, 09126 Chemnitz, Germany

3) The Collective Center for the Belgian technology industry, Didier.Garray@sirris.be, Rue Bois Saint-Jean 12, B-4102 Seraing, Belgium

\section{Keywords}

Assembly Injection Molding, Chemical Bonding, Forming, Interface Design, Polymer-Metal Hybrid, Powder Coating

\begin{abstract}
In this study, the shaping and assembly behavior of adhesive polymer-metal-composites was investigated in an international cooperation using two step curable uretdione-polyester-based powder coatings (IPF development [1, 2]) which act simultaneously as a reactive adhesive agent and as a high-quality surface finish. To create the composite, a thermoplastic polyurethane (TPU) layer with good compatibility to the powder coating was over-molded onto a powder coated aluminum substrate. A polyamide (PA6) layer was over-molded on to the TPU layer to create a stiff composite structure with possibilities for further functionalization. The TPU-layer in between the metal substrate and the polymer top layer acts as a stress and strain compensation layer. These loads are caused by thermal expansion (under fluctuating temperatures) and external forces/deformation. Another key feature of the composite is the innovative process chain. The powder coating can resist high deformation and therefore the coating is suitable for a future application on to a metal substrate using a coil coating procedure. In addition, the coil could be easily implemented into a production line as a semi-finished product. The prefinished coated metal substrate could be formed (e.g. incremental forming, deep drawing) and inserted in the over-molding procedure. This overall shortened process chain allows not only an effective fabrication of pre-coated semi-finished materials and polymer-metal-joints in high quantities by saving process steps (e.g. cleaning steps, glue application) but also a higher versatility in the following composite production.
\end{abstract}

\section{Introduction}

Polymer-metal-joints are often used in automotive or lightweight applications. The connection between the materials is based primarily on form- or force-fit which allows combinations of incompatible materials by using a specific part design [3]. In many cases these design methods are not appropriate for the application. Adhesive bonds are needed to enable a stronger joint. Difficulties in joining metals and polymers are primarily caused by large differences in the thermal expansion coefficients and poor molecular adhesion. Recent studies deal with adhesive bonds which are realized with the use of adhesive agents $[4,5]$ or modifications, like Plasma treatment [6]. Other studies discuss the bonding behavior between light metals, such as aluminum and titanium, and reinforced fiber laminates with or without form-fit [7] and a number of studies focus on manufacturing of hybrid parts using injection molding based processes $[8,9]$. In these processes, the metal components are inserted into the injection mold and are over-molded by a thermoplastic material. The machine clamping force or the injection pressure can also be used for the deformation of the metal inserts using the so-called Polymer Injection Forming (PIF) process [10]. Higher deformation can be reached with Polymer 
Injection Compression Forming (PICF). Polymer-polymer-composites (e.g. assembly injection molding) are being investigated extensively [11].

For the application process, it is important to make a distinction between the state of the adhesion promoter. If the adhesion promoter is in the liquid state (lacquer), it can be applied by spraying, knife coating, rolling, brushing or printing. If the adhesion promoter is in the solid state (e.g. foil), there are different laminating techniques (e.g. calendaring, hot air pressing). In general, an additional pretreatment of the substrate is necessary to ensure an optimal adhesion whereby the metal surface is cleaned and activated. Furthermore, the adhesion promoter usually has to be applied within a temperature controlled process (e.g. continuous oven).

As a result of the work presented here, a pretreatment step can be bypassed by replacing the adhesion promoter with a novel two step curable and highly flexible powder coating which gives excellent adhesive bonding, surface sealing and finishing. Furthermore, additional cleaning, pretreatment and corrosion protection/coating steps of the resulting polymer-metal-hybrid structure can be omitted. Through this integrative approach, the process chain for the production of multimaterial hybrid components can be designed more efficiently in terms of resources and energy and therefore also costs (Fig. 1).
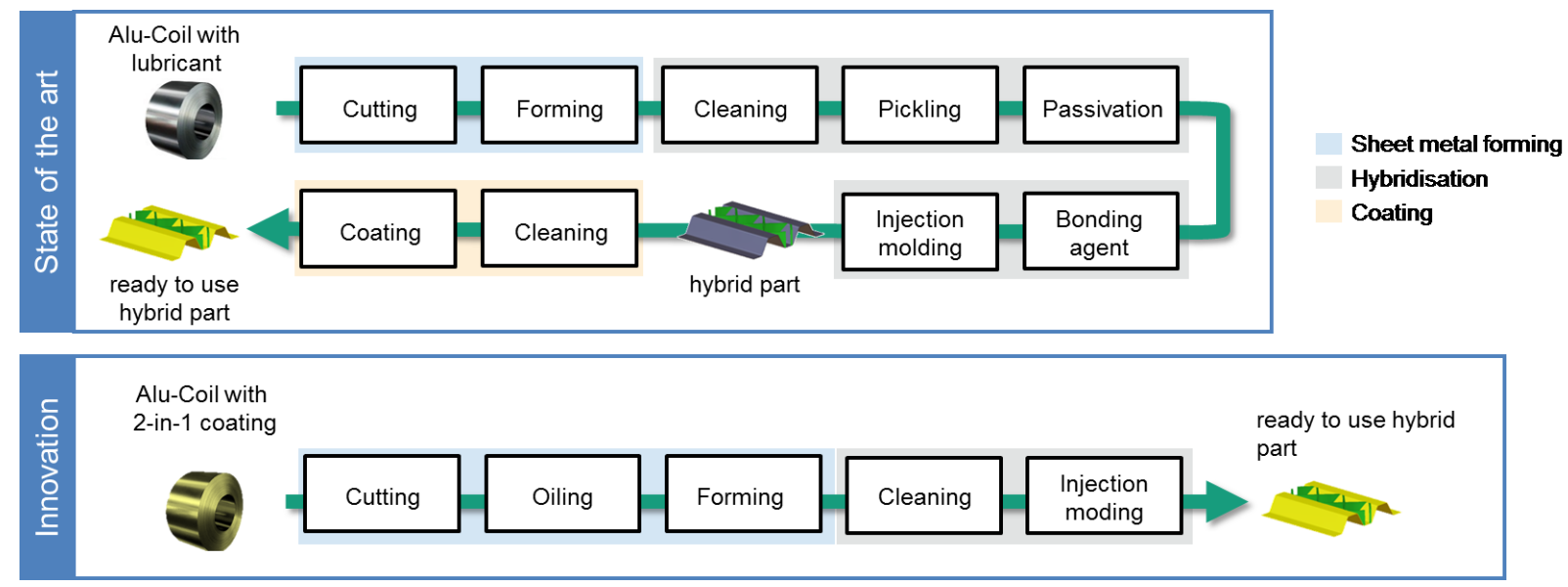

Figure 1: Process chain for polymer-metal-hybrids

\section{Project: "Prefinished metal polymer hybrid parts"}

The developments presented in this paper are the results of the CORNET project "PreFiHy Prefinished metal polymer hybrid parts" (IGF-No. 122 EBR, [12]). The project consortium consists of the German partners: "Leibniz-Institut für Polymerforschung Dresden e.V." (IPF), the "Fraunhofer Institute of Machine Tools and Forming Technology" (IWU) and the Belgian partners: "Centre for Research in Metallurgy" (CRM) and "The collective centre for and by the technological industry" (Sirris). The consortium deals with the development of efficient technologies and process chains for hybrid parts.

\section{Materials, Processes and Methods}

The hybrid system discussed in this article consists of a pretreated aluminum substrate (EN AW-6016T4), newly developed IPF powder coating formulations, a thermoplastic urethane elastomer (TPU) layer and a functional Polyamide 6 layer. A number of investigations were done to evaluate the performance of the individual interfaces and production steps. The layer composition is shown in Fig. 2. The composition of the hybrid system allows manufacturing using different sequences. For high quantities the coating could directly be applied to the coil or cut sheets. The process chain for low quantities uses preformed substrates (3D structures) for the coating procedure. To verify some of the advantages of the novel joining technology, a demonstrator part was manufactured with the small- 
quantity process chain, where the substrate was coated after forming. Due to small part sizes and low quantities, the pretreatments and coatings were applied manually.

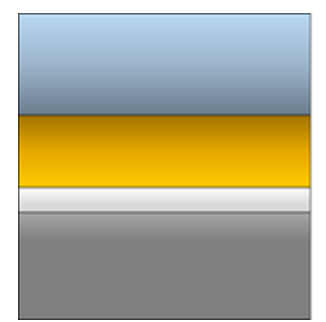

Thermoplastic functionalization Layer (PA)

Thermoplastic elastomer Layer (TPU)

IPF powder coating

Pretreated aluminium sheet

Figure 2: Layer design

\subsection{Aluminum Substrate Pretreatment}

The flexibility of the powder coating layer and the substrate pretreatment (e.g. corrosion protection layer) play a significant role for the formability of the pre-coated aluminum substrates and the effectiveness of the bonding in the hybrid. Consequently, two pretreatment methods were investigated by CRM and examined for their suitability for complex forming operations and corrosion protection tests. The "Henkel" pretreatment method (cleaning, pickling and passivation with commercially available materials from "Henkel Adhesive Technologies") is the state of the art for the IPF coating procedure. Additionally, CRM modified and adapted a pretreatment method from "Deleuze S.A." (Silica-Epoxy-based) [12]. The aluminum alloy EN AW-6014-T4, which was provided by the project partner "Novelis-Switzerland", was used as a sheet material.

\subsection{Powder Coating}

The newly developed powder coating materials are based on commercially available uretdione (internally blocked isocyanates) crosslinkers and $\mathrm{OH}$-functionalized polyester resins. The primary focus of the coating formulation development was the variation of the $\mathrm{OH}$-group number of the polymer resin to show the influence on the adhesive strength of the joint. Additionally, the postformability of the coating system, as well as the surface appearance should be maintained at a high level. Finally, the storage stability of the powder material itself should be enhanced in this manner. By choosing suitable matrix components the crosslinked layers exhibit outstanding flexibility and weathering stability even at low curing temperatures between $140^{\circ} \mathrm{C}$ and $150{ }^{\circ} \mathrm{C}$, provided that a special catalyst system (which was developed at the IPF earlier) is used [1]. Using these catalysts, the crosslinking takes place in a two-step mechanism (Fig. 3). Each reaction step can be controlled by choosing a suitable temperature and time. Curing temperatures $\leq 150^{\circ} \mathrm{C}$ selectively result in a polyallophanate network. At temperatures above $>>160^{\circ} \mathrm{C}$ these structures can be completely and rapidly converted into a polyurethane network. In the project, the second crosslinking stage was used as a latent reactive adhesive layer for chemical reactive bonding of the plastic component to the precoated metal substrate during injection molding through the formation of covalent bonds. Therefore, the TPU is applied with a melt temperature of $265^{\circ} \mathrm{C}$. In this way, high adhesion strengths to thermoplastic polyurethanes (TPU) can be achieved. 


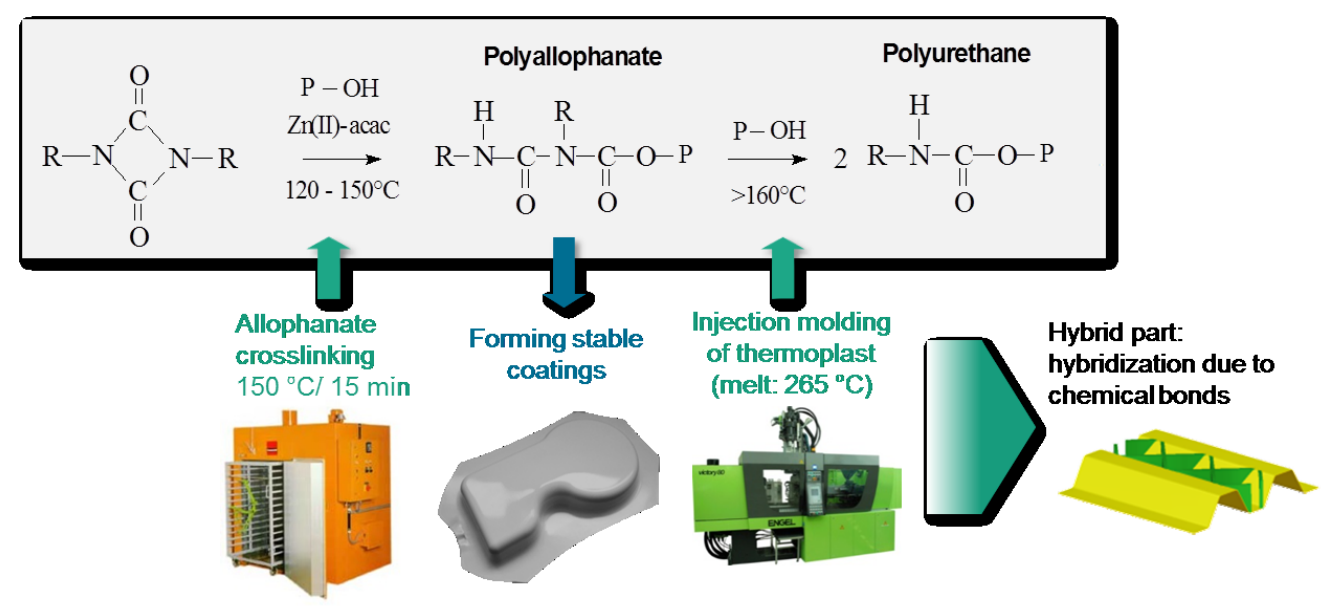

Figure 3: Two-step reaction mechanism of the powder coating

A decisive criterion for the evaluation of preferred powder coating variants for further investigations was the glass transition temperature $\left(T_{g}\right)$ in the powder state. Industry specifications demand a $\mathrm{T}_{\mathrm{g}} \geq 40^{\circ} \mathrm{C}$. In order to evaluate the film flexibility as a crucial demand for subsequent complex forming operations (e.g. deep drawing) Erichsen cupping and Impact tests, according to the relevant standards (DIN EN ISO 1520 [13] or ASTM 2794 [14]), were used. All coating variants which were included in this paper fulfilled the minimum requirements (Erichsen cupping depth $>8.5 \mathrm{~mm}$; Impact $\geq 160$ inch*lb), were found to be highly flexible and offered a high substrate adhesion by using these standard tests.

\subsection{Substrate Deformation Evaluation}

The Fraunhofer IWU developed a test concept based on the loads experienced during deep drawing to evaluate the forming stability/post-formability of the powder coated metal sheets. The loads applied to the crosslinked polyallophanate system were simulated by standard laboratory scale tests. A tensile test (test sample with uniform width) was used to simulate a uniaxial tensile load. A biaxial stress state without friction was induced using the forming limit curve (FLC) test (only square sample for 3D deformation). With the cupping test it was possible to investigate different stress states and the influence of friction on the coating variants. The forming results obtained were evaluated with four evaluation criteria: the adhesive strength, the degree of gloss, the roughness and the layer thickness. The evaluation criteria were determined before and after the experiment using the following standard methods: the gloss measurement was carried out by a reflection measurement at defined angles, the roughness was tested in the center section (touch slice measurement), a pull-off test according to DIN EN ISO 4624 [15] was used to measure the adhesive strength and the layer thickness was measured non-destructively by an eddy current measurement or using cross sections. With the aid of an evaluation matrix preferred variants were defined after the experiments.

\subsection{Thermoplastic Layers}

In addition to the adhesive strength of the polyallophonate-crosslinked film to the aluminum substrate, the adherence of the injection-molded thermoplastic to the powder film surface is important. In a first step, peel tests for selected coatings pretreated using the "Henkel" standard method were carried out at IPF, in accordance with VDI 2019 [16] (Fig. 4), in order to determine the bond strength. For the elastic component a TPU, Elastollan C85A10 from BASF, which showed excellent bonding strength with the coating $(\approx 250 \mathrm{~N}$ average peel force) and with the Polyamide functionalization layers $(\approx 300 \mathrm{~N}$ average peel force) in the preliminary investigations, was used. The rigid thermoplastic component of the demonstrator part was a Polyamide 6, Ultramid B3S from BASF. Injection molding was performed using an ENGEL Victory 80 two component assembly injection molding machine. 

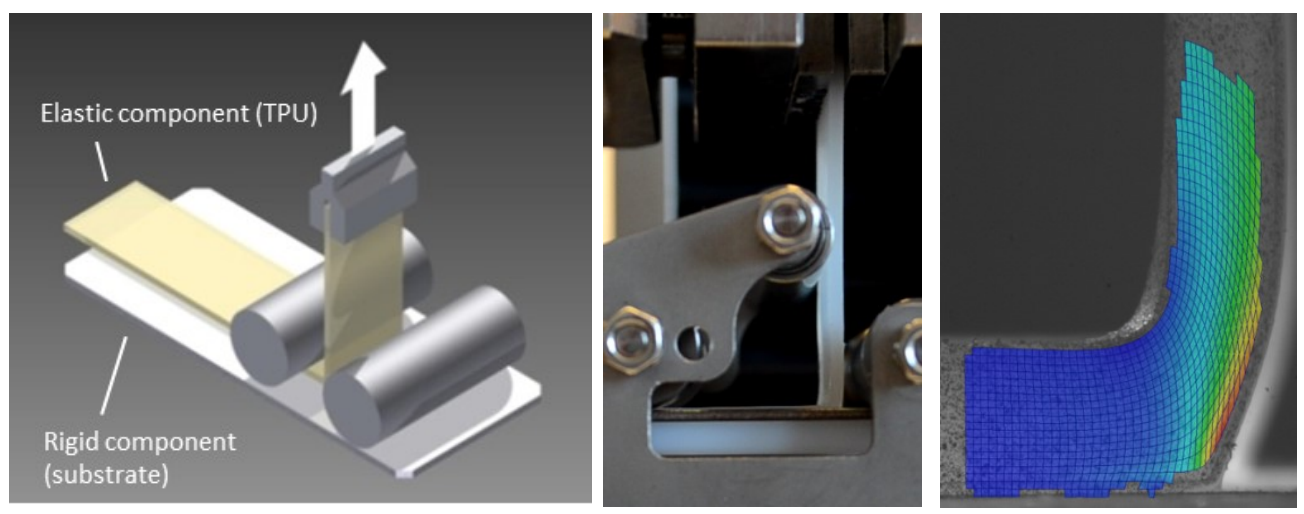

Figure 4: Peel test, scheme (left), testing procedure (middle) and Aramis-analysis of the peeling zone (right)

\subsection{Assessment matrix}

According to VDI 2225 [17], the assessment criteria were ranked into five categories from "very good" to "unsatisfactory". For this purpose, appropriate classes were defined for each criterion. Since bond strength is particularly important for hybrid components, the bond strength has the highest weighting factor. For evaluating the individual coating variants, grades were assigned depending on the results of the testing methods. The combination of the weighting factor and the grades assigned gave a single point value. The ranking of each of the coating variants was then determined from the sum of the individual point values.

\subsection{Demonstrator part}

The advantages of the hybrid technology in the form of an innovative 2-in-1 powder coating are illustrated using an interior part from the automotive sector (Fig. 5). The shape of the prototype, in the form of a 3D-contoured metallic insert, is overmolded with a thermoplast. For the first step of the production, the aluminum insert (EN AW-6016-T4) was formed incrementally (Fig. 6). A universal mandrel with a diameter of $30 \mathrm{~mm}$ was used as the forming tool. Due to the nearly vertical edges of the component and to increase the shape accuracy, a rigid counter tool in the form of a steel mold was used. The production time of the insert was about 30 minutes at a pitch of $0.2 \mathrm{~mm}$ and a feed of $6 \mathrm{~m} / \mathrm{min}$. The lubricant that was used is commercially available forming oil. The samples were pretreated and coated after incremental forming because of the very high contact forces produced during the incremental forming process and represent the low quantity process chain. Injection molding of the TPU intermediate layer and the PA6 frame of the part were performed by the Belgian partner SIRRIS.

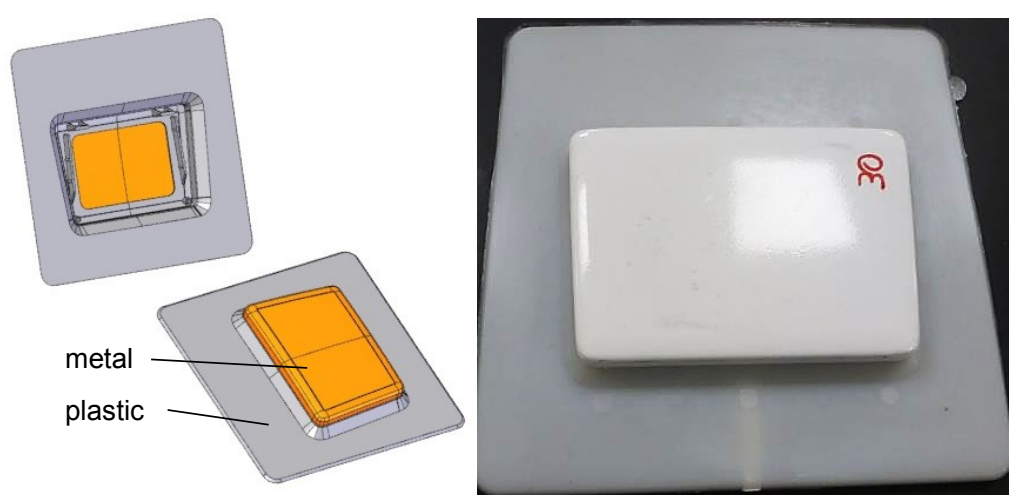

Figure 5: Demonstrator part, left: CAE scheme, right: final part 

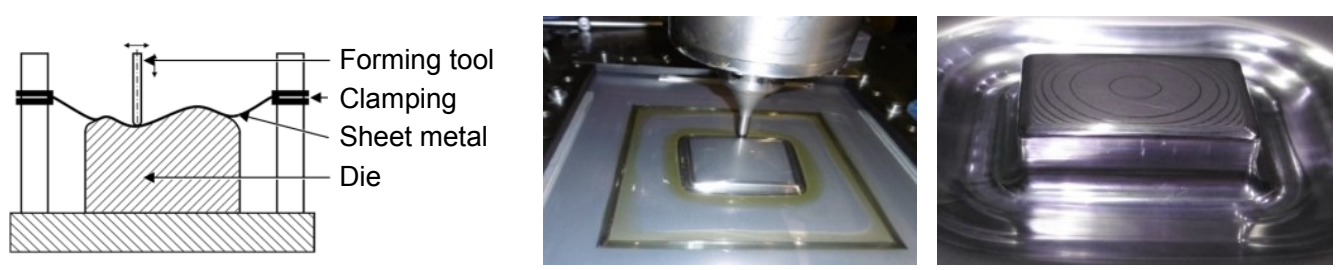

Figure 6: Incremental forming of the metallic insert

\section{Results}

\subsection{Adhesion evaluation - peel test}

For the first evaluation, peel tests were performed with "Henkel" pre-treated aluminum substrates, coated with several powder coating formulations, selected according to the preliminary results, and overmolded with TPU. The results expressed as an average peel force are shown in Fig. 7 . The reference powder coating with the initial IPF formulation is indicated in Fig. 7 (No 33). Some of the coatings show a higher average peel force. In the second step, a number of coatings were selected using the assessment matrix. For further investigations, coating No 10, No 17, the reference coating, No 33, and coating No 21 since it showed the best results for a mat surface.will be considered for high gloss coating systems.

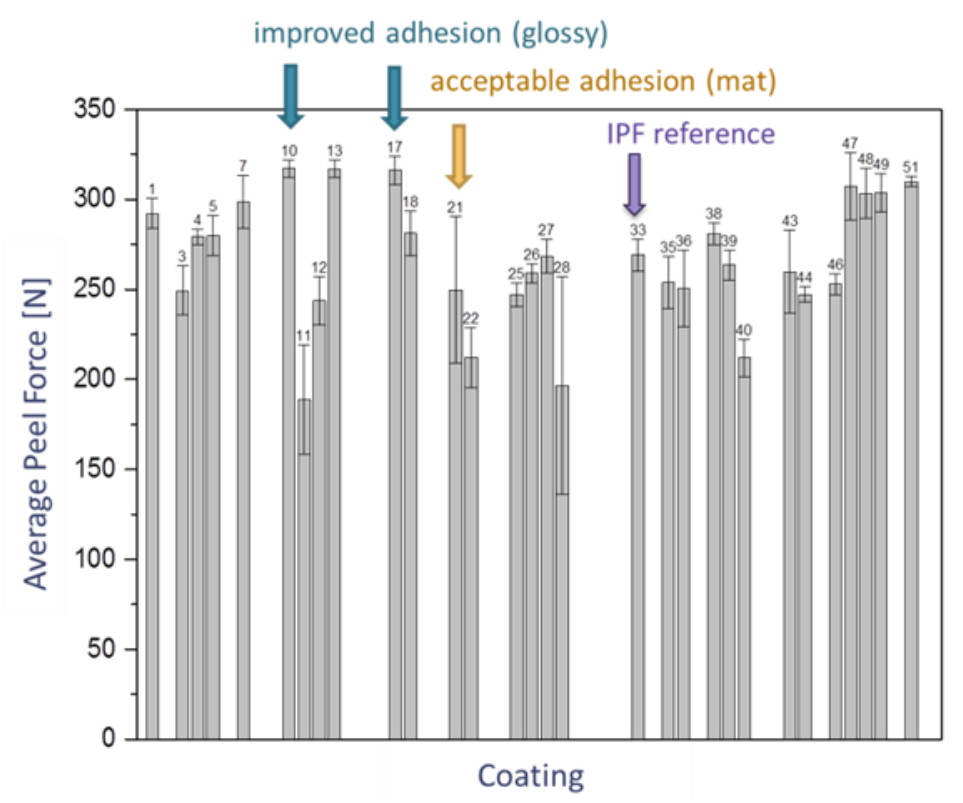

Figure 7: Peel test results: average peel force for several coatings and Henkel pretreatment

Using the chosen lacquer systems and the reference coating material, further peeling tests using the novel CRM pretreatment method (Silica-Epoxy) were performed. The evaluation of the results shows that the type of pretreatment has different effects on the peel forces (Fig. 8). Slightly higher peeling forces of the CRM pretreatment for the coatings 10, 17 and 33, but lower peeling forces for the mat coating number 21 were observed. It was also noteworthy that there was no separation of the powder coating from the aluminum substrate in any of the samples that were tested. 


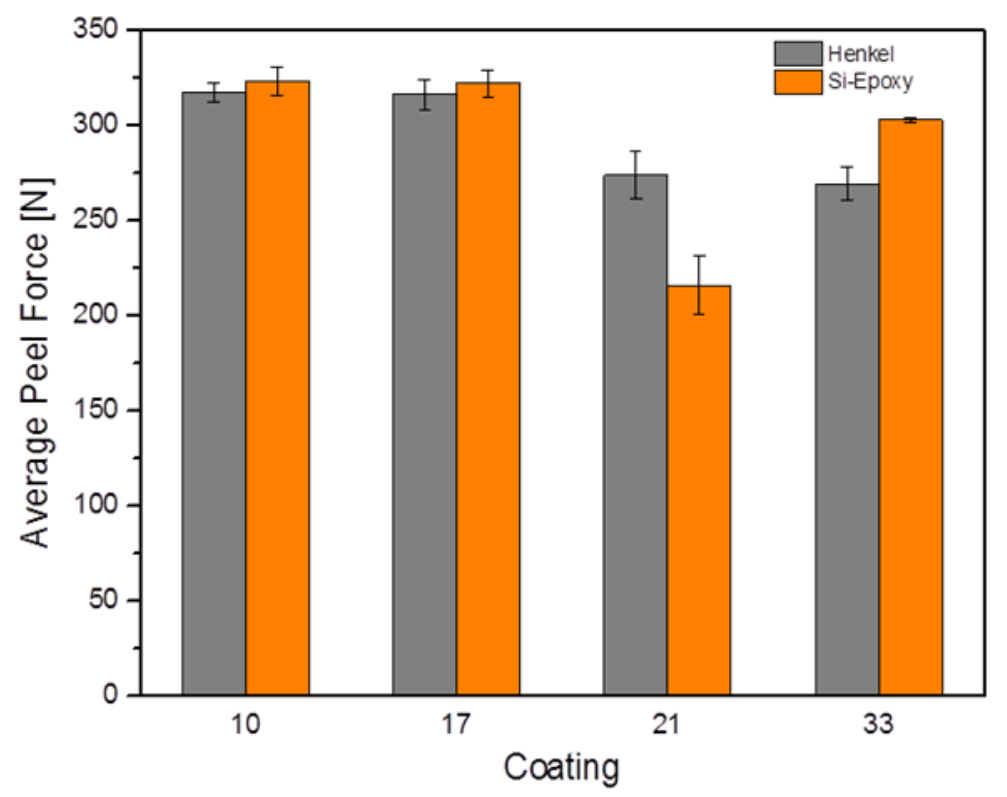

Figure 8: Average peel forces for selected coatings using Henkel and CRM pretreatment

\subsection{Forming evaluation (high quantity process chain)}

For all the selected coatings the forming stability has been proven in laboratory scale. No forminginduced delaminations or cracks were detected. The different samples were mainly distinguished by the degree of gloss and the adhesive strength after forming. An overview of the test specimen for the forming evaluation is shown in Fig. 9, left. Cross sections taken out of the region with the highest deformations showed a constant and homogenous film thickness for the investigated coatings (Fig. 9, right).
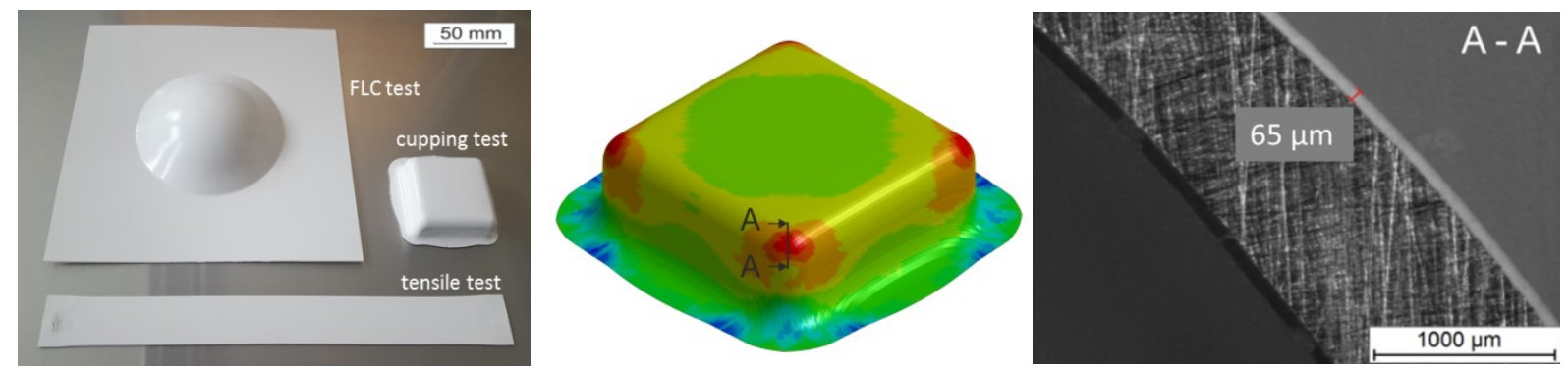

Figure 9: Specimen for the evaluation of the formability (left), forming simulation (cupping test, middle) and cross section in area of highest thinning on the example of the cupping test (right)

\subsection{Forming operations for demonstrator part (low quantity process chain)}

Since conventional CAM software was used to generate the forming path, the rebounding behavior of the sheet metal material was not considered. The resulting shape deviation may lead to the fact that the metallic insert cannot be positioned exactly within the cavity of the mold and hence, flashing could result. However, brief trials conducted to investigate this have shown that the maximum shape deviation of approx. $0.3 \mathrm{~mm}$ at the edge of the sheet was not problematic with respect to the shape of the demonstrator part that was used (Fig. 10). There were no positioning problems and there was no flashing. 

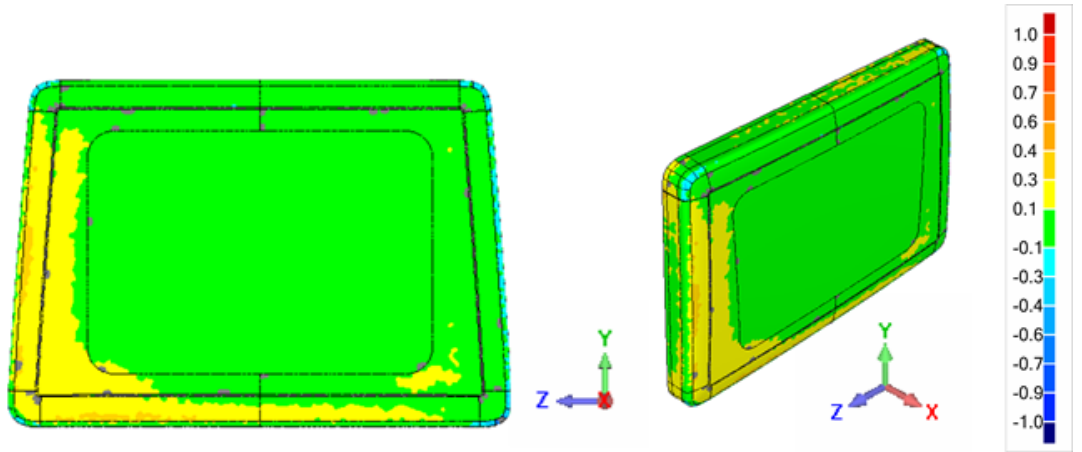

Figure 10: 3D-measurement of the metallic insert, shape deviation in $\mathrm{mm}$ from the CAD contour

\subsection{Overmolding of demonstrator part}

Since no structural requirements with respect to stiffness or strength were specified for the prototype which was designed as an interior component, non-standardized 3-point bending tests were carried out for the purpose of testing and comparing the mechanical composite properties. The results of the 3-point bending test showed that, despite the large deformation, no failure of the composite was induced (Fig. 11). Delamination of the composites occurred in none of the samples during the testing.
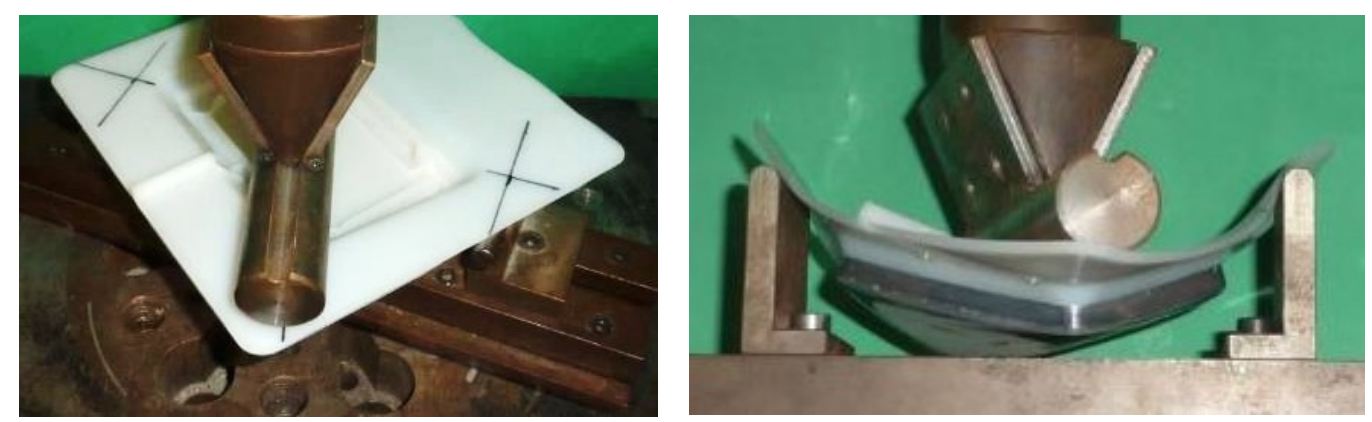

Figure 11: Example of a non-standardized 3-point bending test construction

\section{Discussion and conclusion}

Within the framework of the CORNET project, a novel joining technology for polymer-metalcomposites was developed made possible through the use of an innovative low temperature crosslinking powder coating. The stable, functionalized 2-in-1 powder coating combines the function of surface finishing, adhesion-promoting and material bonding of the hybrid during injection molding without any additional pretreatment of the insert.

Based on these fundamentals, a number of novel powder coating formulations were developed by IPF using the special crosslinking mechanism. The aim of the coating development was to achieve the highest possible bond strength while maintaining a high forming stability. Following projects will focus on the coil coating application technology and modified curing approaches. Fraunhofer IWU has developed a test concept to evaluate the forming stability of the various coatings as a function of the powder coating formulation and the pretreatment method that was used. Using this method, suitable coatings were selected by applying an assessment matrix. With the help of an automotive interior part, the applicability and the advantages of the novel hybrid bonding technology were demonstrated by SIRRIS with a complex 3D-geometry following the low quantity process chain (coating of preformed substrates). A suitable demonstrator part for the high quantity process chain, with coated coils and subsequent forming operations, was not investigated in the project but has been shown to be viable and will be verified in future investigations. 
In summary, it was shown that a low-cost technology has been developed on the basis of the project results, enabling the industry to efficiently produce hybrid composites with excellent bond strength. By eliminating cost-intense pretreatment steps, the process chain can be shortened and costs saved.

\section{Acknowledgments}

This research project (Cornet "PreFiHy", IGF-No. 122 EBR) of the European Research Association for Sheet Metal Working (EFB) has been funded by the AiF within the programme for sponsorship by Industrial Joint Research (IGF) of the German Federal Ministry of Economic Affairs and Energy based on an enactment of the German Parliament. The authors would like to thank CRM for the cooperation and the experimental support. The associated tool sets for the demonstrator part were provided by the Belgian SME "Simonis Plastics".

\section{References}

[1] Gedan-Smolka, M.; Lehmann, F.; Lehmann, D.: Catalysis in uretdione powder coatings enables innovative processing lines. Polymer Preprints, 44 (2003) 1, pp. 58 - 59

[2] Gedan-Smolka, M.; Kühnert, I.; Scholz, P.; Fischer, M. et al.: Powder coating films with latent adhesive function for metal-plastic hybrids. In: EURADH 2016, Glasgow, GB, Proceedings, pp. 228-231.

[3] Ehrenstein, G. W.: Mit Kunststoffen konstruieren. München: Hanser, 2007.

[4] Erickson, P. W.; Plueddemann, E. P.: Composite Materials 6. New York: Academic Press, 1974.

[5] Risthaus, M.: Eine dauerhafte Verbindung. Kunststoffe, 62 (3) (2010), pp. 85-87.

[6] Drummer, D.; Schmachtenberg, E.; Hülder, G.; Meister, S.: MK ${ }^{2}-$ A novel assembly injection molding process for the combination of functional metal surfaces with polymer structures. J. Mater. Proc. Techn. 210 (14 ) (2010), pp. 1852-1857. doi: 10.1016/j.jmatprotec.2010.06.020

[7] Gude, M.; Hufenbach, W.; Kupfer, R.; Freund, A.; Vogel, C.: Development of novel form-locked joints for textile reinforced thermoplastices and metallic components, J. Mater. Proc. Techn., 216 (2015), pp. 140-145. doi: 10.1016/j.jmatprotec.2014.09.007

[8] Jäschke, A.; Dajek, U.: Dachrahmen in Hybridbauweise. VDI-Tagungsband, 4260 (2004), pp. 2545, 2004.

[9] Zhao, G.: Spritzgegossene, tragende Kunststoff-Metall-Hybridstrukturen. Dissertation, Universität Erlangen-Nürnberg, 2001.

[10] Hussain, M. M.; Rauscher, B.; Tekkaya, A. E.: Wirkmedienbasierte Herstellung hybrider MetallKunststoff-Verbundbauteile mit Kunststoffschmelzen als Druckmedium. In: Innovationsforum Verfahrensintegration, Dortmund, 2012.

[11] Al-Sheyyab, A; Müller, T.; Kühnert, I.; Schmachtenberg, E: Short process for hybrid Structures. Kunststoffe international, 12 (2007), pp. 81-8.

[12] Scholz, P. et al.: PreFiHy - Prefinished light metal polymer hybrid parts. Hannover: EFB, EFB Forschungsbericht, Nr. 459, 2017.

[13] DIN EN ISO 1520:2007-11: Paints and varnishes - Cupping test (ISO 1520:2006); German version EN ISO 1520:2006.

[14] ASTM D2794 - 93(2010): Standard Test Method for Resistance of Organic Coatings to the Effects of Rapid Deformation (Impact).

[15] DIN EN ISO 4624:2014-06: Paints and varnishes - Pull-off test for adhesion (ISO/DIS 4624:2014); German version EN ISO 4624:2014.

[16] VDI 2019:2016-04: Testing the adhesion of thermoplastic elastomers (TPE) on substrates.

[17] VDI 2225 Blatt 1:1997-11: Design engineering methodics - Engineering design at optimum cost Valuation of costs. 